\title{
Palliative Radiation Therapy for Advanced Gastrointestinal Cancer
}

\author{
Naoya Murakami ${ }^{a}$ Keiichi Nakagawa ${ }^{a}$ Hideomi Yamashita ${ }^{a}$ Hirokazu Nagawa $^{b}$

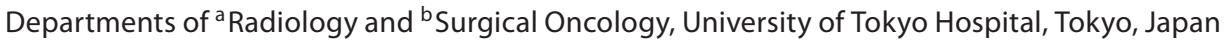

\section{Key Words}

Palliative radiation therapy - Brachytherapy •

Gastrointestinal cancer $\cdot$ Esophageal cancer $\cdot$ Gastric

cancer $\cdot$ Colorectal cancer

\begin{abstract}
Patients with locally advanced disease can have significant local symptoms. The most common symptoms from local extension are pain, bleeding (hematemesis, melena) and obstruction (dysphagia, vomiting). These can cause a significant impact on a patient's quality of life. Radiation therapy is used to control these symptoms with modern 3-dimensional conformal techniques or brachytherapy. The aim of this study was therefore to review the outcome of palliative radiation therapy in patients with symptomatic locally advanced or recurrent gastrointestinal cancer.
\end{abstract}

Copyright $\odot 2008$ S. Karger AG, Basel

\section{Introduction}

Worldwide, many people suffer from gastrointestinal cancer. About 400,000 patients are diagnosed yearly as having esophageal cancer worldwide, and more than 330,000 die from this disease. Every year about 870,000 patients are diagnosed as having gastric cancer world- wide; more than 640,000 die from this disease. About 940,000 new cases of colorectal cancer are diagnosed yearly and 490,000 patients die from this disease [1]. Although the main modality to eradicate the disease is surgery, many patients cannot receive operation because of the advanced disease stage or medical condition or recurrence of the disease. Given that such patients cannot receive operation for curative intent, they suffer symptoms from advanced disease and need palliative therapy. In this setting, radiotherapy with or without chemotherapy offers such frail patients who are not tough enough to receive operation meaningful symptom relief with acceptable complications. In this article, we review palliative radiotherapy for gastrointestinal cancer.

\section{Esophageal Cancer}

Over $50 \%$ of the patients with esophageal cancer have inoperable disease at presentation due to advanced disease, metastasis or poor general condition [2]. The majority of patients need palliative treatment to relieve symptoms such as dysphagia, pain or bleeding. At present, several treatment modalities are available for palliation of inoperable esophageal cancer. The treatment options most commonly used nowadays include stent placement [3-7], LASER therapy $[8,9]$, external beam irradiation

\section{KARGER \\ Fax +41613061234 E-Mail karger@karger.ch} www.karger.com

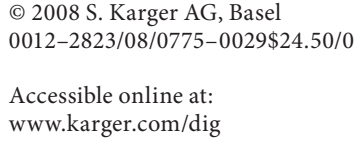

Tel. +81 83815 5411, E-Mail ore-murakami@hotmail.co.jp 


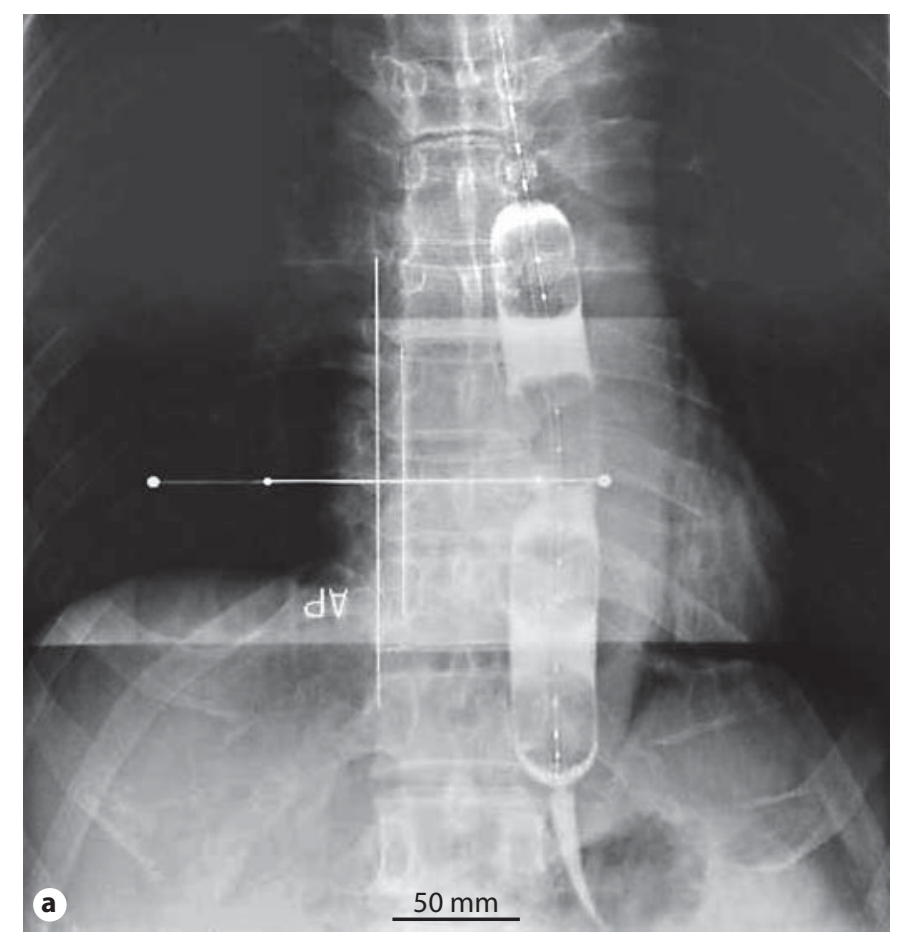

Fig. 1. a X-ray shows an esophageal applicator inserted to the esophagus. b Pretreatment CT scan of esophageal wall thickening with tumor. c Posttreatment CT scan shows shrunk tumor after the treatment.

combined with brachytherapy $[10,11]$ and brachytherapy as a single treatment (fig. 1) [12-19]. A disadvantage of LASER therapy is that this procedure requires repeat treatment sessions to achieve and maintain a good condition $[8,9]$, but repeat treatment is not feasible for patients in a poor medical condition. A combined treatment of external beam radiation with brachytherapy is often too intensive for patients of poor performance status. Therefore, in many patients with inoperable disease, placement of metal stent or single-dose brachytherapy is used for the palliation of dysphagia. One randomized trial has been published for the palliation of dysphagia from esophageal cancer [20]. In total 209 patients were randomized to single-dose (12 Gy) brachytherapy or stent placement (Ultraflex stent). Dysphagia improved more rapidly after stent placement than after single brachytherrapy, but long-term relief of dysphagia and health-related quality of life scores were better after brachytherapy. Compli-
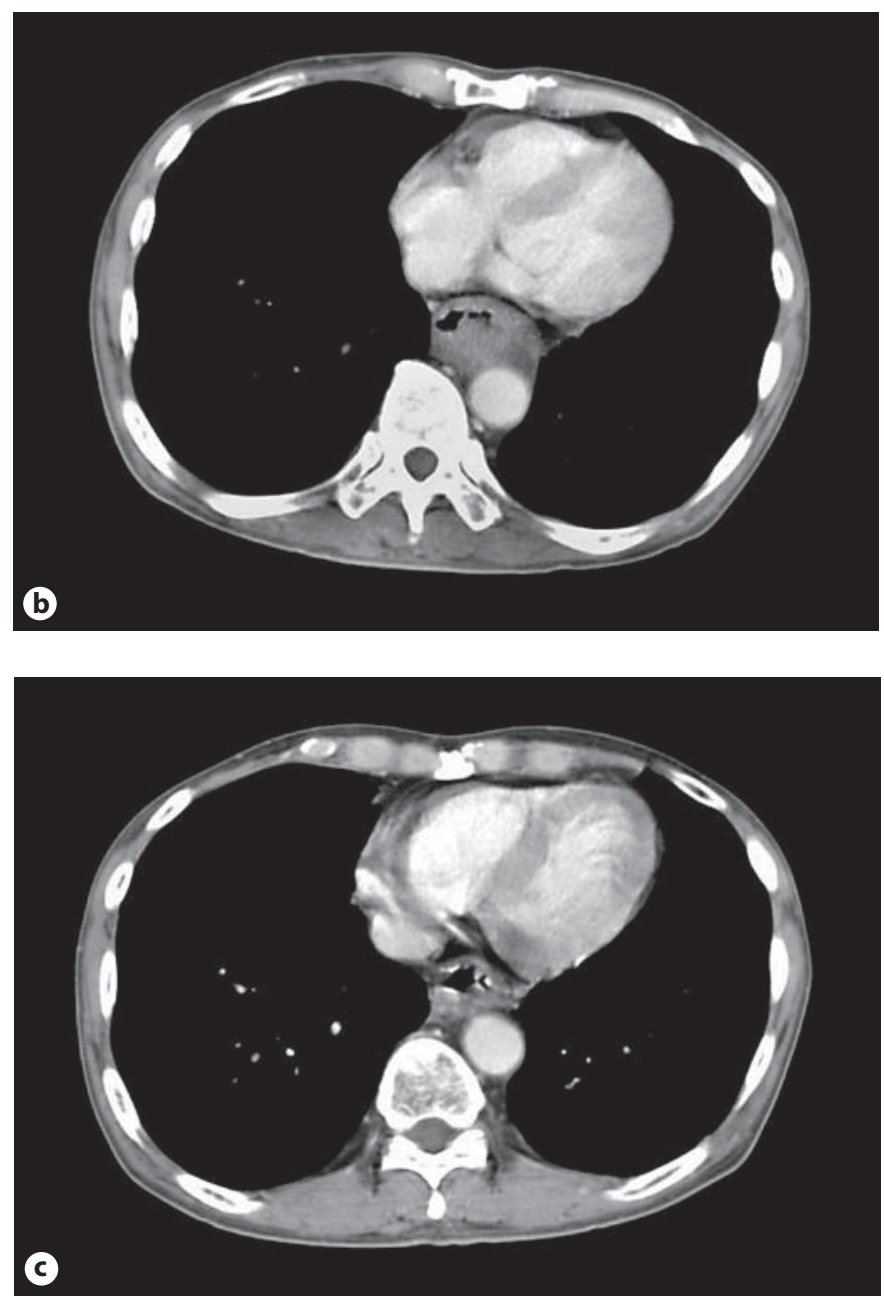

cations occurred more frequently after stent placement (total complications: 33 vs. $21 \%$ ), especially hemorrhage. The treatment groups did not differ for persistent or recurrent dysphagia, about $40 \%$ of either modality group of patients required some kind of second therapy. Whether a single treatment of 12-Gy brachytherapy was the optimum dose, or whether a raised or fractionated dose might improve the biological effects of brachytherapy, is debatable. Different doses of brachytherapy were compared previously in 172 patients with advanced esophageal (mainly squamous cell) carcinoma [16]. With respect to dysphagia-free survival and persistent tumor growth, the patients who received 16 Gy in 2 sessions or 18 Gy in 3 sessions did significantly better than those who received 12 Gy in 2 sessions after treatment. Homs et al. [20] concluded in their paper that single-dose brachytherapy is preferable to stent placement as the initial treatment for patients with dysphagia from inoperable esophageal can- 
Table 1. Treatment results: unresectable or residual gastric cancer

\begin{tabular}{|c|c|c|c|c|c|}
\hline Reference & $\mathrm{n}$ & Treatment & Radiation therapy & Chemotherapy & Results \\
\hline \multicolumn{6}{|l|}{ Randomized } \\
\hline Mayo Clinic [28] & 48 & $\mathrm{EBRT} \pm \mathrm{CT}$ & $\begin{array}{l}35-37.5 \text { Gy in } \\
4-5 \text { weeks }\end{array}$ & 5-FU 1st week of EBRT & $\begin{array}{l}\text { median survival } 13 \text { vs. } 6 \text { months and } \\
5 \text {-year overall survival } 12 \text { vs. } 0 \% \text {, } \\
\text { favoring EBRT }+5 \text {-FU }\end{array}$ \\
\hline GITSG [29] & 90 & $\mathrm{CT} \pm \mathrm{EBRT}$ & $\begin{array}{l}50 \text { Gy split course } \\
\text { in } 8 \text { weeks }\end{array}$ & $\begin{array}{l}\text { 5-FU during EBRT, mainte- } \\
\text { nance 5-FU/MeCCNU 5-FU }\end{array}$ & $\begin{array}{l}\text { 4-year survival } 18 \text { vs. } 7 \% \text {, favoring CT } \\
\text { + EBRT }\end{array}$ \\
\hline EORTIC [30] & 90 & $\mathrm{EBRT} \pm \mathrm{CT}$ & $\begin{array}{l}55.5 \mathrm{~Gy} \\
\text { in } 6 \text { weeks }\end{array}$ & $5-\mathrm{FU}$ & $\begin{array}{l}14 \% \text { long-term survival ( } 3 \text { patients) } \\
\text { with EBRT + 5-FU }\end{array}$ \\
\hline \multicolumn{6}{|l|}{ Retrospective } \\
\hline MGH [31] & 32 & $\mathrm{EBRT} \pm \mathrm{CT}$ & $\begin{array}{l}45-55 \text { Gy } \\
\text { in } 5 \text { weeks }\end{array}$ & $\begin{array}{l}\text { 5-FU during EBRT, mainte- } \\
\text { nance 5-FU/MeCCNU }\end{array}$ & $\begin{array}{l}\text { EBRT + CT; unresectable disease } 14 \\
\text { months median survival; unresectable } \\
\text { and residual disease } 10 \% \text {-year survival }\end{array}$ \\
\hline
\end{tabular}

$\mathrm{EBRT}=$ External beam radiation therapy; $\mathrm{CT}$ = chemotherapy; 5-FU = 5-fluorouracil; MeCCNU = semustine; GITSG = Gastrointestinal Study Group; EORTC = European Organization for Research and Treatment of Cancer; MGH = Massachusetts General Hospital.

cer. Stent placement may be reserved for patients with severe dysphagia whose life expectancy is short and where rapid symptom relief is needed. The consensus guidelines of the American Brachytherapy Society have distinguished several criteria (based on tumor characteristics) to group patients as good candidates, poor candidates and patients with contraindications for brachytherapy [21]. The contraindications for brachytherapy described by the American Brachytherapy Society include an esophageal fistula and a cervical esophageal location of the tumor and a stenotic tumor that cannot be bypassed.

\section{Gastric Cancer}

Patients with localized gastric cancer have a higher 5year survival rate (59\%) compared with regional (21.9\%) or distant disease (3.1\%) [22]. Unfortunately, only 25$40 \%$ of the patients have localized disease at diagnosis and will be able to undergo potentially curative surgical resection [23]. The 3 most common symptoms from local extension are pain, bleeding (hematemesis, melena) and obstruction (dysphagia, vomiting). These can cause a significant impact on a patient's quality of life. Tey et al. [24] retrospectively evaluated the outcome of palliative radiation therapy (RT) alone in patients with symptomatic locally advanced or recurrent gastric cancer managed with modern RT techniques (CT-based radiation). Thirtythree patients with locally advanced/recurrent gastric cancer were treated palliatively with RT alone at the Cancer Institute radiotherapy centers between November 1999 and December 2004. All patients received external beam RT. In the analysis of the response rate, 13 of 24 patients with bleeding (54\%), 2 of 8 patients with pain (25\%) and 2 of 8 patients with obstruction (25\%) responded to radiotherapy. The median duration of response was 140, 102 and 105 days for patients with bleeding, pain and obstruction, and the mean percent net relief (the ratio between the duration of symptom relief and survival multiplied by 100) [25] was $65.3,66.3$ and $71 \%$, respectively. Although efficacy is mainly limited to patients who present with bleeding, external beam RT may still be considered for patients presenting with obstruction or pain because responses are possible. A response rate of at least $25 \%$ is reasonable, given that most patients may have failed chemotherapy and only received RT for palliative therapy. If patients do respond to radiation, the responses are often durable no matter what the symptom is.

If the general condition of patients with inoperable advanced gastric cancer is good enough to undergo chemoradiotherapy, not only symptom relief but also survival benefit can be expected by combined-modality therapy (5-year survivals of 5-15\%) [26]. Table 1 shows treatment results of unresectable or residual gastric cancer treated by radiotherapy with or without chemotherapy [27-31]. Most 


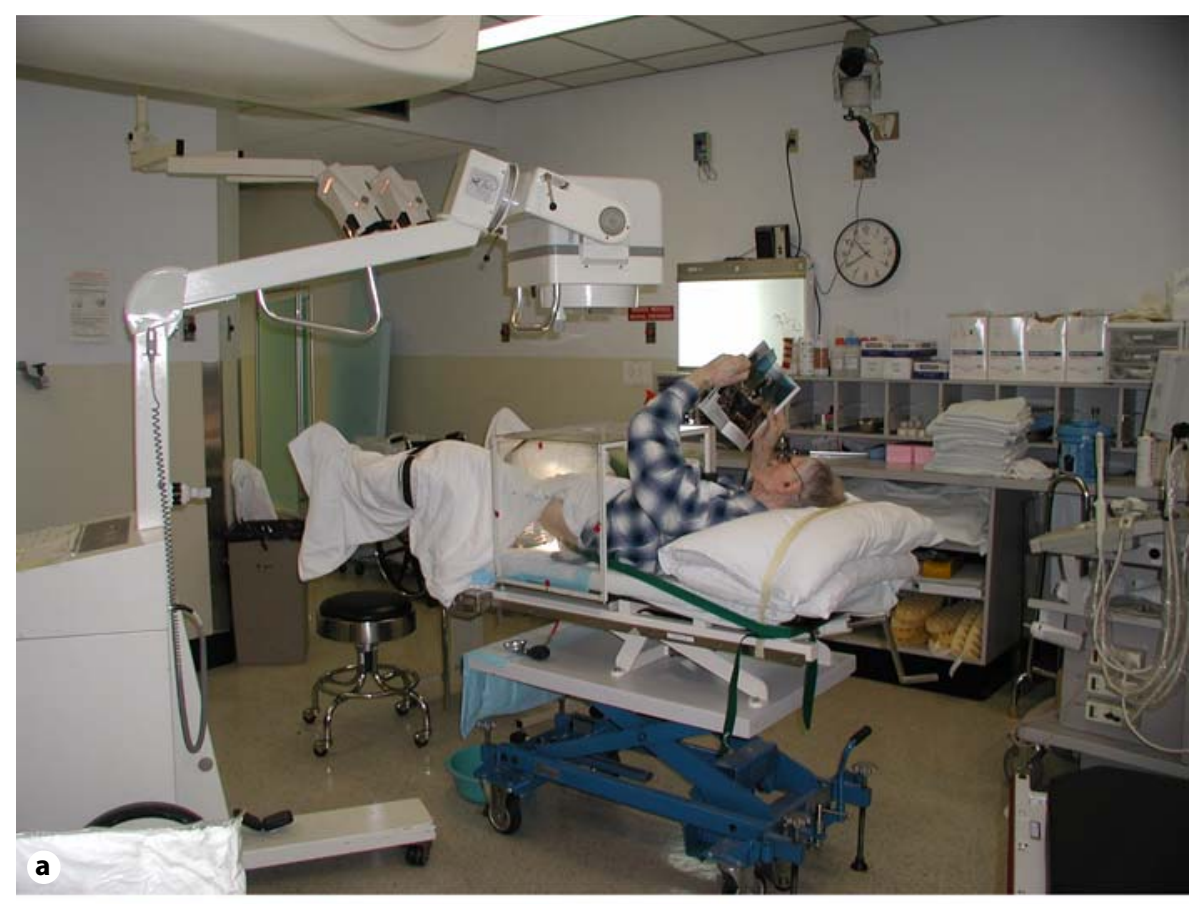

Fig. 2. a Patient lying on the treatment couch awake during treatment. b Rectal applicator inserted through anal verge with patient lying in the lithotomy position.

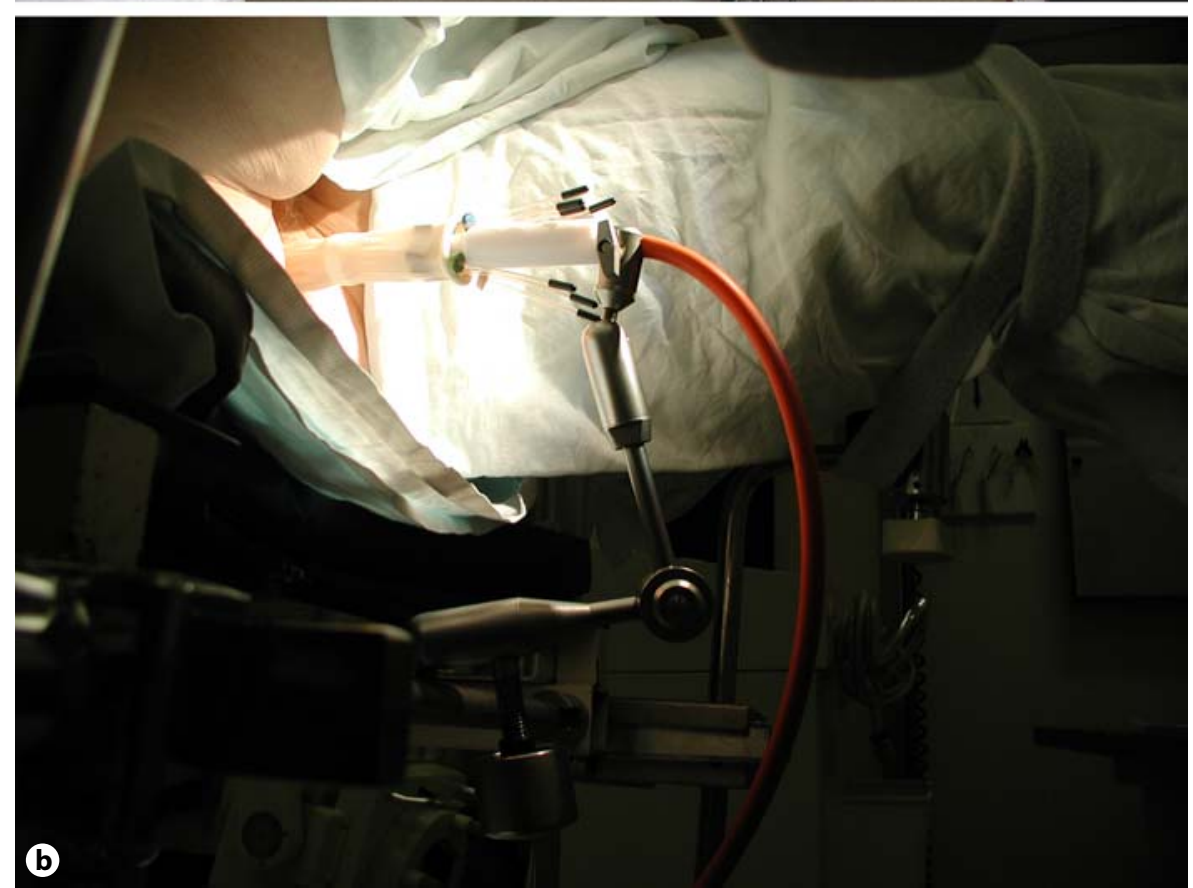

phase III trials for unresectable or residual gastric cancer show an advantage for combined-modality treatment over single-modality treatment. Radiation doses range from 35 to $55.5 \mathrm{~Gy}$ in 1.5-2.0 fractions. Most chemotherapies mainly consist of 5-fluorouracil. These populations of patients achieve a 5 -year overall survival of about $15 \%$ by combined treatment of radiation and chemotherapy.

\section{Colorectal Cancer}

The mainstay of treatment for rectal and low sigmoid colon cancer is surgical resection with or without adjuvant chemoradiation. There are, however, patients for whom this is inappropriate either because of their general condition or because of recurrent tumor or locally 


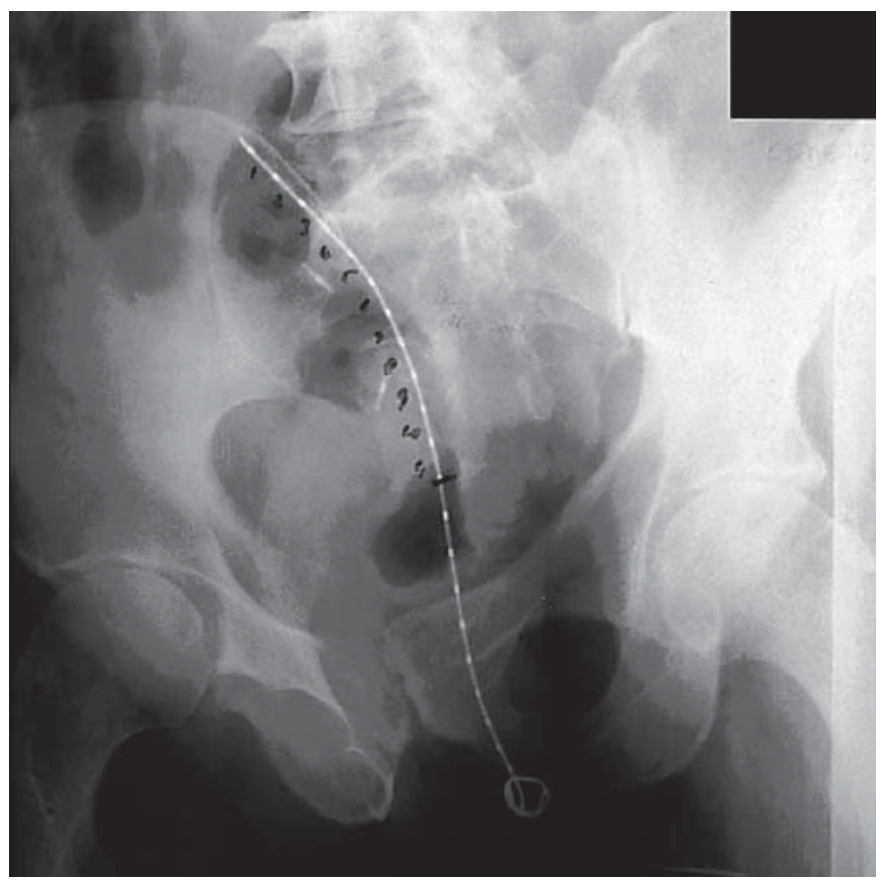

Fig. 3. X-ray demonstrating flexible high-dose-rate catheter with marker wire in situ in position with a surgical clip marking the superior and inferior extents of the tumor passed through.

Table 2. Presenting symptoms

\begin{tabular}{lr}
\hline Bleeding & 28 \\
Mucous discharge & 14 \\
Diarrhea & 10 \\
Pain & 8 \\
Tenesmus & 5 \\
Constipation & 4 \\
Fecal incontinence & 2 \\
Obstruction & 1 \\
\hline
\end{tabular}

No patient was symptom free; 20 had a single symptom, of whom 10 had bleeding; 17 had 2 symptoms and 6 had 3 symptoms, hence the total number of symptoms is 72 .

advanced tumor in face of widespread metastatic disease. In this setting, radiotherapy or chemotherapy may have an important role for local tumor control and symptom relief. External beam techniques to treat this area may be limited in achieving a high dose by the tolerance of large and small bowel, bladder and skin. Brachytherapy carries the advantage of being able to deliver a localized high dose of radiation with rapid fall-off of dose and sparing of adjacent normal tissues. Access to the rectal lumen is

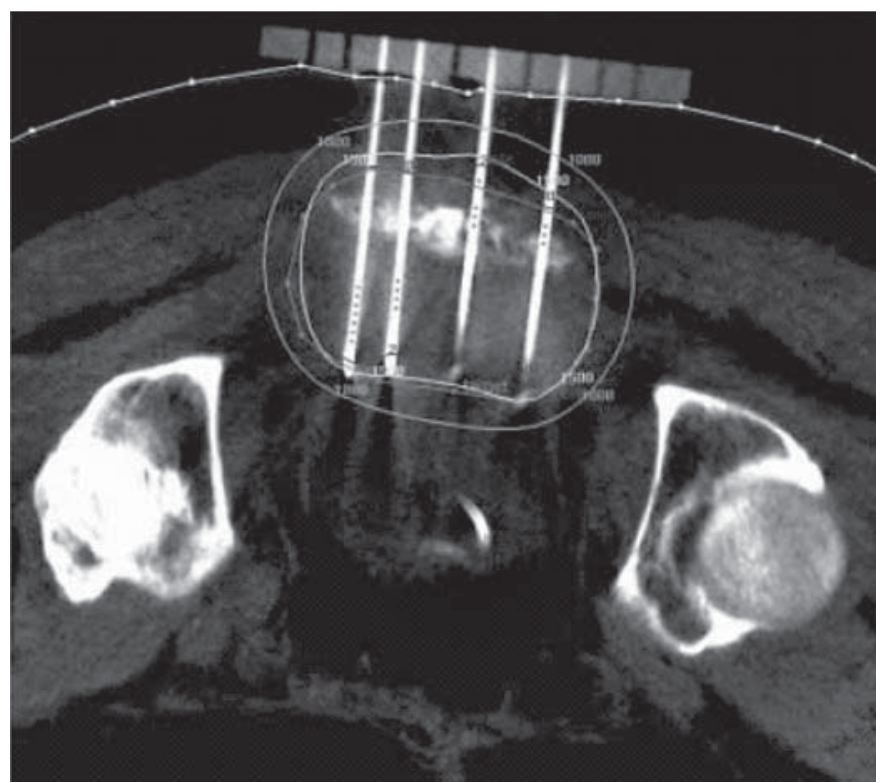

Fig. 4. CT scan showing the isodose distribution for a patient treated using the transsacral implant technique.

Table 3. Response rate and duration

\begin{tabular}{|c|c|c|c|c|}
\hline & $\begin{array}{l}\text { Mucous } \\
(\mathrm{n}=14)\end{array}$ & $\begin{array}{l}\text { Bleeding } \\
(\mathrm{n}=28)\end{array}$ & $\begin{array}{l}\text { Pain } \\
(n=8)\end{array}$ & $\begin{array}{l}\text { Diarrhea } \\
(\mathrm{n}=10)\end{array}$ \\
\hline Complete response & $4(28)$ & $16(57)$ & $4(50)$ & $6(60)$ \\
\hline Partial response & $5(36)$ & $2(7)$ & $3(37)$ & $4(40)$ \\
\hline No change & 4 & 0 & 0 & 0 \\
\hline Lost to follow-up & 1 & 10 & 1 & 0 \\
\hline \multicolumn{5}{|l|}{ Response duration } \\
\hline Median, months & 4 & 10 & 7 & 7 \\
\hline Range, months & $1-28$ & $1-35$ & $1-10$ & $1-10$ \\
\hline
\end{tabular}

Figures in parentheses are percentages.

simple and therefore provides an ideal opportunity for delivering high-dose local radiation by brachytherapy. Hoskin et al. [32] reported 10 years of experience of intraluminal brachytherapy for advanced inoperable rectal carcinoma, both boost treatment alongside external beam chemoradiation and sole treatment for small localized tumors at Mount Vernon Hospital. Between October 1992 and December 2001, a total of 50 patients were treated with brachytherapy. Treatment is delivered in the high- 


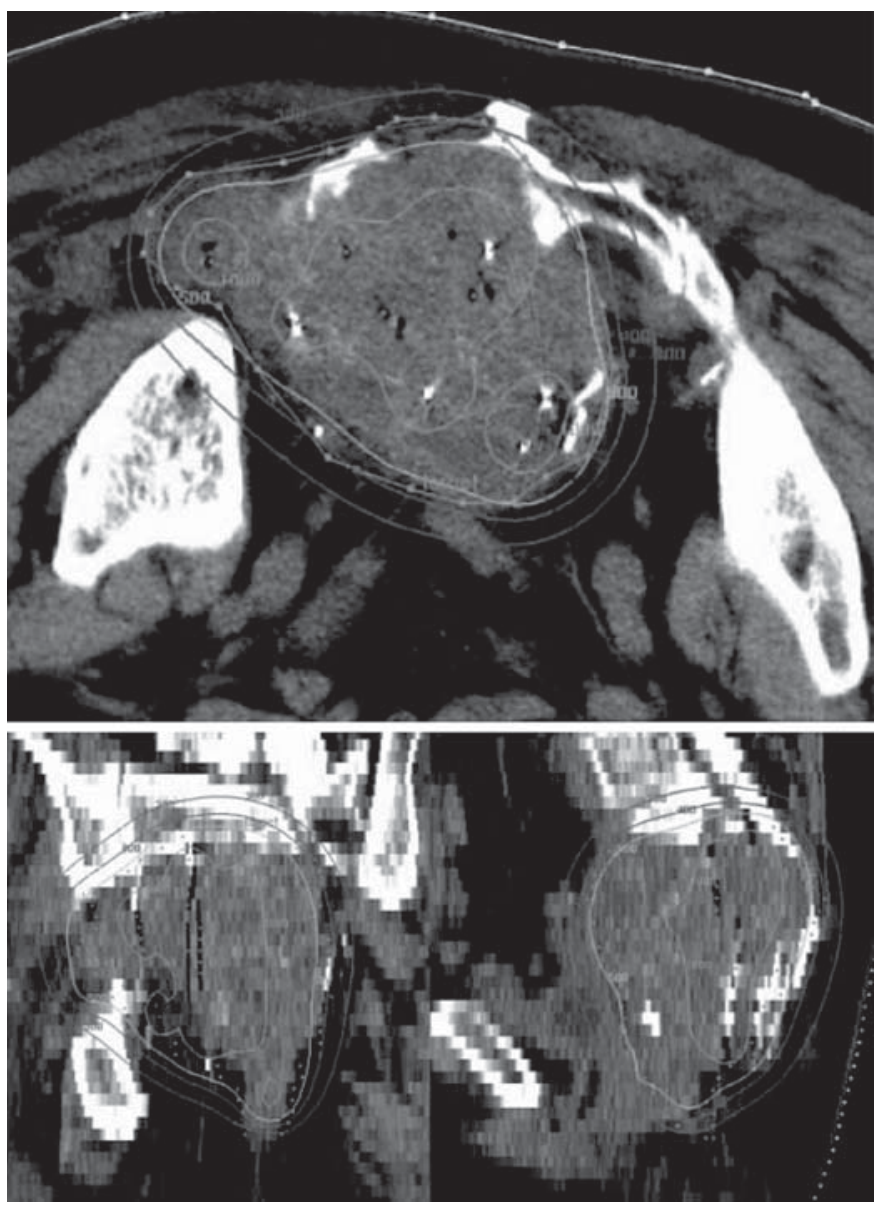

Fig. 5. Example of the CT-guided transperineal technique. The isodose lines are superimposed on the transverse, sagittal and coronal reconstructed CT slices.

dose-rate afterloading suite with the patient awake, lying on the treatment couch and a local anesthetic gel around the anal orifice is used but no sedation or general anesthesia (fig. 2). In most circumstances where the tumor is plete response (60 and 57\%, respectively); mucous dis-

high-dose-rate intraluminal brachytherapy is a simple outpatient procedure with minimal acute toxicity for the management of anorectal carcinoma. It has a particular role in the treatment of the frail elderly patient unable to tolerate more intensive treatment offering effective and durable palliation of advanced disease.

If the locally advanced or recurrent tumor is large enough to be covered with a single intraluminal applicator or the tumor obstructs the lumen to insert the applicator, interstitial brachytherapy is applied. Kolotas et al. [33] treated 38 patients with recurrent rectal cancer after surgery. The mean tumor volume was $336.5 \mathrm{ml}$ and they used either transsacral implantation (in case of sacrum invasion, fig. 4) with 10-15-Gy single dose or transperineal implantation (fig. 5) with 5-Gy fractions twice daily for 30-40 Gy. Although the tumor response was not so good (6/38 partial remission, 28/38 stable disease and $4 / 38$ local progression), they achieved a meaningful symptom relief [pain: $34 / 38$ patients (89.5\%), reduction of analgesics: $25 / 38(65.7 \%)]$ and durable effect (percent net pain relief $=66 \%$ ). There was no mortality associated with the treatment, and morbidity was limited: 1 patient with fistula and 1 with ulceration of the perineal area. The approaches described above for locally unresectable rectal cancer recurrences can be performed safely and can provide effective palliation. high-dose-rate brachytherapy technique delivers high-dose fractions to the tumor in a short time while keeping the dose to the surrounding organs at a low level. This aspect is especially important for preirradiated patients.

\section{Disclosure Statement}

The authors declare that no financial or other conflict of interest exists in relation to the content of the article. palpable, check X-rays are not taken, but where localization with a surgical clip is used, a portable film will be taken as shown in figure 3 . The incidence of presenting symptoms is shown in table 2 and symptom response incidence and duration is displayed in table 3 for the 4 most common symptoms, mucous discharge, bleeding, pain and diarrhea. Diarrhea and pain have high rates of comcharge was improved in $64 \%$, but complete response was more difficult to achieve. There was 1 case of a radionecrotic ulcer and 1 stricture reported, both in patients treated with radical chemoradiation and brachytherapy boost. No other late effects are recorded. In summary,

References

Digestion 2008;77(suppl 1):29-35
1 Parkin DM, Bray FI, Devesa SS: Cancer burden in the year 2000: the global picture. Eur J Cancer 2001;37(suppl 8):S4-S66.

$\checkmark 2$ Sagar PM, Gauperaa T, Sue-Ling H, et al: An audit of the treatment of cancer of the oesophagus. Gut 1994;35:941-945.

3 De Palma GD, Galloro G, Sivero L, et al: Selfexpanding metal stents for palliation of inoperable carcinoma of the esophagus and gastroesophageal junction. Am J Gastroenterol 1995;90:2140-2142.

-4 Siersema PD, Hop WC, van Blankenstein M, et al: A comparison of 3 types of covered metal stents for the palliation of patients with dysphagia caused by esophagogastric carcinoma: a prospective, randomized study. Gastrointest Endosc 2001;54:145-153.
Murakami/Nakagawa/Yamashita/ Nagawa 
5 Kozarek RA, Raltz S, Brugge WR, et al: Prospective multicenter trial of esophageal Zstent placement for malignant dysphagia and tracheoesophageal fistula. Gastrointest Endosc 1996;44:562-567.

6 Raijman I, Siddeque I, Ajani J, et al: Palliation of management dysphagia and fistulae with coated expandable metal stents: experience with 101 patients. Gastrointest Endosc 1998;48:172-179.

7 Bartelsman JF, Bruno MJ, Jensema AJ, et al: Palliation of patients with esophagogastric neoplasms by insertion of a covered expandable modified Gianturco-Z endoprosthesis: experiences in 153 patients. Gastrointest Endosc 2000;51:134-138.

$>8$ Spencer GM, Thorpe SM, Blackman GM, et al: Laser augmented by brachytherapy versus laser alone in the palliation of adenocarcinoma of the oesophagus and cardia: a randomized study. Gut 2002;50:224-227.

$\checkmark 9$ Dallal HJ, Smith GD, Grieve DC, et al: A randomized trial of thermal ablative therapy versus expandable metal stents in the palliative treatment of patients with esophageal carcinoma. Gastrointest Endosc 2001;54: 549-557.

-10 Taal BG, Aleman BM, Koning CC, et al: High dose rate brachytherapy before external beam irradiation in inoperable oesophageal cancer. Br J Cancer 1996;74:1452-1457.

-11 Schraube P, Fritz P, Wannenmacher MF: Combined endoluminal and external irradiation of inoperable oesophageal carcinoma. Radiother Oncol 1997;44:45-51.

-12 Homs MY, Eijkenboom WM, Coen VL, et al: High dose rate brachytherapy for the palliation of malignant dysphagia. Radiother Oncol 2003; 66:327-332.

-13 Brewster AE, Davidson SE, Makin WP, et al: Intraluminal brachytherapy using the high dose rate microSelectron in the palliation of carcinoma of the oesophagus. Clin Oncol (R Coll Radiol) 1995;7:102-105.

$\checkmark 14$ Rowland CG, Pagliero KM: Intracavitary irradiation in palliation of carcinoma of oesophagus and cardia. Lancet 1985;2:981983.
15 Kulhavy M, Sur RK, Levin CV, et al: Optimization of single-fraction high dose rate intraluminal brachytherapy in palliation of advanced esophageal cancer: a preliminary report. Endocurie Hypertherm Oncol 1995; 11:235-239.

16 Sur RK, Donde B, Levin VC, et al: Fractionated high dose rate intraluminal brachytherapy in palliation of advanced esophageal cancer. Int J Radiat Oncol Biol Phys 1998;40: 447-553.

17 Sur RK, Levin CV, Donde B, et al: Prospective randomized trial of HDR brachytherapy as a sole modality in palliation of advanced esophageal carcinoma - an International Atomic Energy Agency study. Int J Radiat Oncol Biol Phys 2002;53:127-133.

18 Sharma V, Mahantshetty U, Dinshaw KA, et al: Palliation of advanced/recurrent esophageal carcinoma with high-dose-rate brachytherapy. Int J Radiat Oncol Biol Phys 2002; 52:310-315.

19 Jager J, Langendijk H, Pannebakker M, et al: A single session of intraluminal brachytherapy in palliation of esophageal cancer. Radiother Oncol 1995;37:237-240.

20 Homs MY, Steyerberg EW, Eijkenboom WM, et al: Single-dose brachytherapy versus metal stent placement for the palliation of dysphagia from oesophageal cancer: multicentre randomized trial. Lancet 2004;364: 1497-1504.

21 Gaspar LE, Nag S, Herskovic A, et al: American Brachytherapy Society (ABS) consensus guidelines for brachytherapy of esophageal cancer. Clinical Research Committee, American Brachytherapy Society, Philadelphia, PA. Int J Radiat Oncol Biol Phys 1997;38:127132.

22 Ries LAG, Eisner M, Kosary CL: SEER Cancer Statistics Review, 1975-2002. Bethesda, National Cancer Institute, 2004.

23 Perez C, Brady LW, Halperin EC: Principles and Practice of Radiation Oncology, ed 4. Philadelphia, Lippincott Williams \& Wilkins, 2004.
24 Tey J, Back MF, Shakespeare TP, Mukherjee RK, Lu JJ, Lee KM, Wong LC, Leong CN, Zhu $\mathrm{M}$ : The role of palliative radiation therapy in symptomatic locally advanced gastric cancer. Int J Radiat Oncol Biol Phys 2007;67: 385-388.

25 Salazar OM, Rubin P, Hendrickson FR, et al: Single-dose half-body irradiation for palliation of multiple bone metastasis from solid tumor: final RTOG report. Cancer 1986;58: 29-36.

-26 Hazard L, O’Connor J, Scaife C: Role of radiation therapy in gastric adenocarcinoma. World J Gastroenterol 2006;12:1511-1520.

$>27$ Hazard L, O'Connor J, Scaife C: Role of radiation therapy in gastric adenocarcinoma. World J Gastroenterol 2006;12:1511-1520.

28 Moertel CG, Childs DS Jr, Reitemeier RJ, Colby MY Jr, Holbrook MA: Combined 5fluorouracil and supervoltage radiation therapy of locally unresectable gastrointestinal cancer. Lancet 1969;2:865-867.

29 Schein P, Novak H; for GITSG: Combined modality therapy (XRT-chemo) versus chemotherapy alone for locally unresectable gastric cancer. Cancer Chemother Pharmacol 1982;49:1771.

30 Bleiberg H, Goffin JC, Dalesio O, Buyse M, Pector JC, Gignoux M, Roussel A, Samana G, Michel J, Gerard A, et al: Adjuvant radiotherapy and chemotherapy in resectable gastric cancer. A randomized trial of the gastrointestinal tract cancer cooperative group of the EORTC. Eur J Surg Oncol 1989;15:535543.

-31 Gunderson LL, Hoskins RB, Cohen AC, Kaufman S, Wood WC, Carey RW: Combined modality treatment of gastric cancer. Int J Radiat Oncol Biol Phys 1983;9:965975.

32 Hoskin PJ, de Canha SM, Bownes P, Bryant L, Glynne Jones R: High dose rate afterloading intraluminal brachytherapy for advanced inoperable rectal carcinoma. Radiother Oncol 2004;73:195-198.

-33 Kolotas C, Röddiger S, Strassmann G, Martin T, Tselis N, Aebersold DM, Baltas D, Zamboglou N: Palliative interstitial HDR brachytherapy for recurrent rectal cancer. Strahlenther Onkol 2003;179:458-463. 